\title{
A Typology of Actional-Operational Modes in Earth Science and Implications for Science Literacy Instruction
}

\author{
Amy Alexandra Wilson \\ Utah State University \\ Emma Eccles Jones College of Education and Human Services \\ School of Teacher Education and Leadership \\ 2805 Old Main Hill Drive \\ Logan, Utah, 84322-2805 \\ email: amyawilson@msn.com \\ phone: (801) 633-7638
}




\begin{abstract}
Framed in theories of social semiotics, this multiple case study describes and categorizes the actional-operational modes used by three middle school earth science teachers throughout the course of one school year. Data included field notes, photographs, and video-recordings of classroom instruction, as well as periodic interviews with the teachers. A constant comparative analysis of the data resulted in the creation of a typology of actional-operational modes according to how they fulfilled the ideational, interpersonal, and textual metafunctions of communication. Six categories of actional-operational modes were identified: gesture, embodied representation, moving objects on flat surfaces, moving objects through three-dimensional space, material representations, and observed phenomena. Multimodal concordance charts were used to identify the affordances and productive constraints of each of these modes. The study offers implications for how fundamental science literacy instruction might be re-conceptualized to more rigorously account for actional-operational texts, including building students' multimodal representational competence and providing comprehension strategy instruction in ways that consider these modes' unique features.
\end{abstract}

Keywords: scientific literacy, social semiotics, earth science education, scientific representation, scientific communication, actional-operational, comprehension strategy instruction, multimodal representational competence 


\section{A Typology of Actional-Operational Modes in Earth Science and Implications for Science Literacy Instruction}

Under the recognition that a variety of representations are central to the process of learning science (Prain \& Waldrip, 2010), a large body of literature has classified or described several modes used in scientific communication — such as images (Han \& Roth, 2006; Topper, 1996), writing (Bazerman, 1988; Fang, 2006) and gestures (Pozzer-Ardenghi \& Roth, 2005; Roth \& Lawless, 2002). The purpose of this multiple case study, conducted within three middle school earth science classrooms, was likewise to examine scientific communication, but with an emphasis on actional-operational modes, defined as modes that are "enacted operationally through many forms of human motor activity other than speech” (Lemke, 1998, p. 87). By examining the ways in which these modes afforded and productively constrained communication, this study highlights how external actional-operational representations can emphasize or omit particular aspects of their referents. The following sections define actionaloperational modes as they relate to theories of social semiotics and literature on scientific communication.

\section{Actional Operational Modes and Scientific Communication}

Despite a widespread consensus that scientific communication in classrooms is often profoundly multimodal (Klein \& Kirkpatrick, 2010; Waldrip, Prain, \& Carolan, 2010), there is no consensus in regards to the terms that should be used to describe multimodal communication. For instance, Yore and Hand (2010; cf. Balaban, 1999) argued that the term 'language'__in its broadest sense" - includes three-dimensional models, images, and any other mode used to communicate scientific concepts (p. 93). Others (Kress, Jewitt, Ogborn, \& Tsatsarelis, 2001), by contrast, have argued that the term 'language' should be exclusively reserved for written words or verbal speech, instead arguing that three-dimensional models are 'representations,' a term that 
foregrounds the relationship between a referent—-such as an atom—and its re-presentation through a signifier — such as Styrofoam balls stuck together through wire.

Still others (Wu \& Puntambekar, 2012) use the term 'representation' to describe modes as diverse as verbal speech and "demonstrations... [that] allow students to experience and manipulate a phenomenon by hand [and to] measure and collect data" (p. 3). This use of the term 'representation' is also potentially problematic in the sense that many demonstrations require the manipulation of natural objects, such as the scratching of a mineral across a ceramic tile to identify its streak. Unlike a photograph (a signifier) representing a mineral (its referent), here, the mineral itself is the object of interpretation and study.

To avoid this obfuscation in terminology, Roth and colleagues (e.g., Roth, Tobin, \& Shaw, 1997) reserved terms such as 're-presentation' or 'inscription' for a wide array of scientific communications such as "graphs, tables, lists, photographs, diagrams, spreadsheets, and equations," (Roth \& McGinn, 1998, p. 37), instead preferring the terms 'nature' or 'object' to describe 'observed phenomena' such as minerals. However, Goodwin (2000) argued that minerals, dirt, and other types of so-called 'nature' are also "human semiotic construal[s]" in the sense that people use them to communicate particular messages in conjunction with other modes and they use particular frameworks for interpreting them (p. 1513).

As these debates suggest, what constitutes 'representation' or 'communication' is contested, especially when addressing actional-operational modes that include hands-on experimentation with a variety of physical mediums. Consistent with theories of social semiotics (e.g., Kress, 2003, 2010), this study uses the term 'text' to refer to "any instance of communication in any mode or in any combination of modes, whether recorded or not" (2003, p. 48). This study assumes that representations, or signifiers that relate to referents, are a subcategory of 'text,' a term which encompasses other potentially overlapping sub-categories such 
as language (written words and verbal speech) and observed phenomena, all of which are often used together in individual acts of communication in science classrooms.

\section{Actional-Operational Modes and Typologies of Scientific Communication}

Of the various modes used for communication, actional-operational modes have been hard to define because they encompass such a wide and seemingly disparate array of forms. Lemke (1998) initially coined the term 'actional-operational' to describe aspects of scientific communication that entail human bodily movement. To be sure, all texts require some type of physical activity in order to be accessible to their users, such as turning a page in a textbook or clicking play on a YouTube video. Actional-operational modes, however, are distinguishable in the sense that their physically observable properties can vary significantly depending upon the physical actions of their users. These physically observable properties include attributes—such as shape, relative location, physical composition, temperature, and speed - that are central to the communicators' messages.

For example, a teacher may seek to communicate the concept of streak by asking her students to slide minerals across a ceramic tile. If a student pressed a given mineral very lightly across the tile, its streak may not appear. In this case, although some of the mineral's characteristics (e.g., shape) were not affected by its user's physical activity, the salient property of streak was not observable due to the user's manipulation. In forms of communication that involve actional-operational modes, then, users' physical activity influences what can be or is communicated.

Many typologies (Gilbert, 2005; Harrison \& Treagust, 2000; Prain \& Waldrip, 2006; Wu \& Puntambekar, 2012) that classify and describe scientific communications have implicitly or explicitly included modes that are shaped by bodily activity, although they emphasize the shaping presence of the body to varying degrees. One obvious means by which the body 
contributes to scientific communication is through gesture, such as when arm and body movement represents the movement of a water particle through the ocean (Wilson, 2010; cf. Lemke, 1998). In other cases, body movements instead point toward or manipulate focal texts in a variety of ways: by changing their location relative to that of other objects, by changing their physical composition through combining them with other objects, or by performing other actions that highlight or reveal properties of the focal object.

In accordance with the idea that all texts involving bodily movement can be grouped under one category of communication, Wu and Puntambekar's (2012) typology of scientific representations identified gestures, demonstrations, manipulatives, and physical models as 'actional-operational' modes, indicating that many modes communicate aspects of their referents only as they are moved by the human body. For instance, students could tilt a globe and revolve it around a light bulb (representing the sun) in order to demonstrate the causes of seasons. In this case, bodily operations on the physical model affect what is communicated: Repeatedly tipping the top of the globe toward and away from the light bulb would communicate incorrect information in the sense that salient features of the representation would not cohere with the salient features of the referent.

Gilbert (2005), by contrast, distinguished physical models as a separate category from gestures under the recognition that three-dimensional models, such as globes, can also be comprehensible and coherent without the accompaniment of body movements. Whereas Gilbert placed physical models in a stand-alone category, (cf. Harrison \& Treagust, 2000), Prain and Waldrip (2006) asserted that physical models and experiments belonged to the same category of scientific representation because they both used three-dimensional space. Although body movements, too, are three-dimensional, Prain and Waldrip placed them in a separate category of representation. Their separation of embodied representations from other three-dimensional 
representations may stem in part from the differences between the physical composition of the body, which is relatively fixed, and the physical composition and special properties (e.g., ability to emit light) of physical models and demonstrations, which can also be used to signify aspects of their referents.

These general typologies of scientific communication include differences that highlight some of the complexities surrounding actional-operational modes. First, the same representation may or may not be identified as actional-operational depending on whether the body performs operations with it. Second, modes that are defined according to the presence of bodily movement in some classification systems (Wu \& Puntambekar, 2012) are instead defined in other classification systems according to other qualities, such as their dimensionality, materiality, or ability to represent items to scale (Gilbert, 2005; Harrison \& Treagust, 2000; Prain \& Waldrip, 2006). The current study seeks to clarify and extend previous taxonomies by outlining a separate typology for actional-operational modes in terms of how they afford and productively constrain scientific communication.

\section{A Social Semiotic Theory of Affordances and Productive Constraints}

Theorists of social semiotics (e.g., Jewitt, 2006; Lemke, 2003; van Leeuwen, 2005) have argued that different modes lend themselves to the communication of particular types of content based on their physical properties in relation to the goals of their users (cf. Gibson, 1979). For example, although one could communicate the positions of the planets in the solar system through writing alone, images afford "spatial and simultaneous representation" (Kress, 2005, p. 14) of planets' relative positions while also depicting gradations of color and size. In this way, although content expressed through one mode may be also expressed through another mode, each mode's affordances enable some aspects of that content to be expressed more 'readily' via that mode (Kress, 2009, p. 57). 
Building on this concept, Prain and Tytler (2012) coined the term 'representational construction affordances' to describe how modes lend themselves to supporting students' understanding of scientific concepts in distinctive ways. After observing an instructional unit on heating and cooling that entailed the use of multiple representations, they asserted that each representation "constrains what can be imagined about the process of evaporation" (p. 16). As an example, they argued that a role play, in which each student's body represented a molecule, “places constraints on molecular size, and focuses attention on spacing and movement" (p. 16).

The features of representations may thus shape the meanings that students construct by what these features can convey - in this case, speed and type of movement and spatial position relative to other bodies - and also by what they cannot convey — in this case, the bodies did not change size or composition, thereby focusing students' attention on the focal properties of movement and spacing. In this way, the productive constraints of multiple representations may be as important as their affordances in effectively communicating scientific concepts (Ainsworth, 1999, 2006).

To a large degree, these descriptions of communicative affordances and constraints focused on what particular representations could (or could not) readily communicate about their referents. In his description of affordances, Kozma (2003) similarly emphasized the preeminence of the relationship between representation and referent when he concluded that science teachers should "provide at least one representational system that has features that explicitly correspond to the entities and processes that underlie physical phenomena" (p. 218). In Halliday's terms $(1973 ; 1978)$, this connection between representation and referent realizes the ideational metafunction of communication. It is through this metafunction that people's texts refer to objects, to relationships between phenomena, or to their experiences of the world. In short, this is the function of a text whereby the text represents something. 
Halliday (1978) argued that representing referents is not the sole function of communication, however. He asserted that all communication also instantiates relative social positions through the interpersonal metafunction, which includes "the particular role that the speaker has chosen to adopt in the situation and the role or role options that he [or she] has chosen to assign to the hearer," including the level and type of participation enacted by each party (p. 46). For instance, a teacher may ask a yes/no question and evaluate the student's oneword answer. In this exchange, the teacher positions himself or herself as an authority and the student as a respondent. Affordances of modes may thus be related to the types of participation they enable various users.

The interpersonal metafunction of communication also enables people to express their attitudes and evaluations or to attempt to influence others' attitudes toward the represented content. Indeed, Tsui and Treagust (2003) have argued that one affordance of multiple representations is their ability to promote positive attitudes toward science. A final role of the interpersonal metafunction is to indicate shared practices among members of a given community. According to McDiarmid, Ball, and Anderson (1989), any representation communicates "implicit messages" about the nature of a discipline, including "the aspects or properties of a subject that distinguish it as a discipline...the ways of knowing and pursuing knowledge...the questions and problems they examine, [and] the ways in which answers are sought and validated" (p. 196). In other words, each scientific representation communicates epistemological messages about how science is known and done, including what distinguishes a scientific community of practice from other social groups. In terms of the interpersonal metafunction, therefore, another affordance of representations includes whether the representation communicates methods of knowing in ways that are authentic to practitioners of science. 
The final metafunction of communication, the textual function, is primarily a connective function whose role is to connect various components of a text to each other and to the social and physical context in which the text is produced. In other words, the textual function meets three requirements: It relates parts of the text to each other; it relates the text to the context in which people are communicating; and it performs these two functions in such a way that the text is coherent both within itself and with the larger world. For example, previous research (Goodwin, 2000; Roth \& Lawless, 2002) has suggested that pointing gestures serve an essential textual function in earth science by connecting communicators' verbal speech to specific components of visual representations. Modes' affordances may therefore also be conceptualized in terms of how they enable connections among other modes within the same act of communication, or in terms of how they foster connections to the surrounding physical and social context.

\section{Research Purpose and Method}

In accordance with these social semiotic theories of modes' affordances and constraints, the purposes of this study were twofold: (a) to classify the actional-operational modes used in three sixth-grade teachers' earth science instruction; and (b) to identify their respective affordances and productive constraints in relation to the ideational, interpersonal, and textual metafunctions of communication. Toward this end, a nine-month multiple case study (Stake, 2006) was designed to investigate the role of actional-operational modes as they were embedded within a larger body of representations.

\section{Research Participants}

Three middle school earth science teachers - Grace, Nancy Rae, and Tracy (pseudonyms) — were purposively selected to participate in this study because they were widely recognized as innovative teachers who made their content accessible to the diverse learners in their respective rural districts in the Southeastern United States. All were deemed 'highly 
qualified' to teach earth science with a minimum of three years of experience in teaching within this field. Grace and Tracy taught both earth science and mathematics; the former had obtained Bachelors and Masters degrees in teaching middle grades mathematics and science, while the latter had obtained a Bachelors' degree was in middle grades education with an emphasis in mathematics, social studies, and science. Nancy Rae taught language arts in addition to earth science after she had obtained a Masters degree in middle grades education with an emphasis in reading and geosciences.

Data were collected from each teacher for one full school year (nine months) in order to ascertain how actional-operational modes were used to communicate a wide array of disciplinary topics. After about five months, however, no new categories or properties of actional-operational modes emerged, indicating that saturation had been reached (Corbin \& Strauss, 2008). For this reason, no additional teachers were selected for further study.

\section{Data Collection}

Three types of data were collected from each teacher: field notes and photographs from observations, video-recordings, and interviews. The author observed 149 total lessons, averaging 64 minutes each, and took field notes describing the teachers' instruction, including photographs of actional-operational modes and other representations used in the classroom. During these observations, 64 lesson segments were videotaped, averaging 8.25 minutes each. The author video-taped lesson segments at the point when teachers began using actional-operational modes.

Additionally, each teacher was interviewed five to seven times in regards to individual instructional episodes, defined as activity segments delineated by a new social configuration (e.g., a shift from whole-class discussion to small-group work) and/or by the introduction of different instructional materials (e.g., a shift from reading a textbook to doing an experiment) (Siskin, 1994). The author purposefully selected instructional episodes for further discussion 
based on two criteria: each instructional episode included an actional-operational mode, and each teacher was interviewed about all categories of actional-operational modes at least once.

During the interviews, teachers received several slips of paper with photographs of the forms of communication - actional-operational and otherwise - used throughout the instructional episode. Teachers ranked these photographs by physically ordering them from most to least important in terms of how well they helped students achieve their instructional objectives, with the option to rank several or all of the photographs as equally important. They then explained the relative strengths and limitations of each representation in relation to their instructional objective. The purpose of these interviews was to ascertain the teachers' perceived affordances and constraints of actional-operational modes as compared to other modes, thereby serving as triangulating data for the author's analysis of affordances and constraints.

The teachers were told that the purpose of the study was to describe their use of scientific representations, and all modes used within each instructional episode were treated equally during the interviews. Moreover, the teachers reported that their instruction was comparable to the instruction they had provided in previous years. For this reason, it is not believed that the teachers increased their use of actional-operational modes or overemphasized their importance in interviews due to the presence of the researcher.

\section{Data Analysis: Phase One}

The data were analyzed in three phases. First, the author and a colleague used modified constant comparative analytic methods (Corbin \& Strauss, 2008) to identify properties and dimensions along which actional-operational modes could be categorized. Following the "analytic strategies of asking questions and making comparisons," (p. 199), we asked questions of individual instances of actional-operational modes, such as "What aspects of the actionaloperational mode are emphasized in the teacher's verbal speech or written instructions?” and 
"What are the focal properties of this mode in relation to the teacher's instructional objectives that are written on the whiteboard?" The following description will illustrate how one category, "Materiality as Text," was developed.

When making comparisons across data points, we found at times that the teachers drew students' attention to the materiality of an object, and students' physical actions (cutting, weighing) were conducted in order to ascertain aspects of the object's physical properties. For instance, Grace's students participated in a lesson whose stated instructional objective was to identify the characteristics of the layers of the earth. During this lesson, Grace's students each cut a chocolate-covered cherry that represented the earth and were instructed to attend to the states of matter and viscosity of each layer. The chocolate-covered cherry was coded as 'materiality as text: states of matter and viscosity.'

In another lesson, Grace's students placed a piece of fluorite on an electronic balance beam and then placed it in a graduated cylinder with water to ascertain water displacement. These actions were conducted in order to gain an approximate measurement of the mineral's density. The fluorite was labeled 'materiality as text: density.' After coding several instances of 'materiality as text,' we made connections across data points, noting that several instances of this code relied on the manipulation of some type of representation of a referent (a chocolate-covered cherry to represent the earth). By contrast, in other instances, students constructed interpretations by attending to a natural object itself.

We labeled all of the former instances as 'material representation' and all of the latter instances as 'observed phenomena' (see Findings section for final definitions of each category). After the author and a colleague developed definitions of codes based on patterns noted across the data, the author coded the entire data set, while her colleague coded ten percent of randomly- 
selected data. We achieved over 85 percent of agreement in assigned codes, indicating they were reliable (Lincoln \& Guba, 1985).

\section{Data Analysis: Phase Two}

Phase Two of data analysis, a micro-analysis of individual moments of communication, was intended to develop a more fine-grained understanding of the affordances and productive constraints of individual actional-operational modes in relation to the ideational, interpersonal, and textual metafunctions of language. Multimodal concordance charts (MCC) (Baldry \& Thibault, 2006) accomplish this task by presenting the data in phases, defined as "co-patterned semiotic selections that are co-deployed in a consistent way over a given stretch of text" (p. 47), distinguished by a separate row on the chart. (See Figure 1 for an analysis of one communicative phase.) Each column of a multimodal concordance chart followed a single mode (e.g., verbal speech) and identified what that mode communicated in each phase in relation to other modes.

For example, in Figure 1, Grace's body movement from Position 5 to Position 6 represented the counter-clockwise movement of the moon around the earth, which occurred over roughly the same length of time as it took the ball to reach other equidistant locations in its orbit. This direction of movement and passage of time were not represented by other modes, such as verbal speech, gesture, or visual image. The ball represented the changing shape of the moon (as seen from the earth) while it remained constantly half-yellow and half-black; this changing shape was likewise not represented through other modes at this point in the orbit. In this way, the threedimensional ball, as transported via Grace's body movements, held affordances in relation to the ideational metafunction by representing the passage of time and by representing how a threedimensional object, though it is objectively 'the same,' appeared differently in relation to students representing the 'earth.' 
For this reason, the bodily movement of the three-dimensional ball was called 'nonredundant,' meaning that it communicated information about the referent expressed by no other modes in the communicative stretch (Crowder, 1996). In addition to identifying what was uniquely communicated by each mode in relation to a referent (the ideational metafunction), the multimodal concordance chart also enabled the analysis of each mode in relation to the interpersonal metafunction by identifying the levels of participation enabled by the representation. Finally, the MCC also included an analysis of modes in relation to the textual metafunction by describing how the modes related to each other and to the larger social and physical context.

We identified six categories of actional-operational modes in Phase One of data analysis; in Phase Two, one multimodal concordance chart was used to analyze one data point from each category. These data points were selected for further analysis because the author had interviewed the teachers about them. After the affordances and productive constraints of each actionaloperational mode had been identified via the use of the MCCs, each chart was compared to the teacher's perceptions of the strengths and limitations of actional-operational modes as expressed in her interview. Similarities and differences between the teachers' and researchers' analyses of each actional-operational mode were identified and noted below each multimodal concordance chart (See Figure 1).

Moreover, after the teachers had ranked the photographs of instructional representations in order of most to least effective in terms of helping students achieve their instructional objective, the author used the findings from Phase One to give labels to the actional-operational modes pictured in each photograph. For instance, the photograph of the chocolate-covered cherry was labeled 'materiality as text: material representation.' Figure 2 summarizes the teachers' 
rankings of representations in each instructional episode, as described in 14 interviews about 14 different instructional episodes.

\section{Data Analysis: Phase Three}

The third phase of data analysis combined the analyses from the first and second phases (CCA and MCC). During Phase One, the data had all been coded and uploaded into NVivo 9, a qualitative data analysis computer software package that allowed for the easy retrieval of data that had been assigned the same code. When "moving object as text: three-dimensional space" was typed in the program's search function, for example, a list of all of the instances that had been assigned this code, including images, appeared onscreen. Prior to writing the section about each mode, the author retrieved other data points with the same code and compared them to the analysis from Phase Two in order to ascertain if similar affordances and productive constraints were evident across more data points. The findings section reports at least one 'telling case' (Rex, 2001) for each category of actional-operational mode. In this instance, a telling case can be defined as a case with similar affordances and productive constraints that were evident across several other data points that had been assigned the same code.

\section{Limitations}

This study is characterized by several limitations. First, the three teachers identified themselves as being middle class and White, but modes often vary depending on the culture of the communicator (Kendon, 2004; Kress, 2010). Although these teachers were considered successful at communicating earth science concepts to diverse students, this study does not enable a discussion of how people with diverse cultural, geographic, or linguistic backgrounds might have used particular modes to meet the needs of a particular group of learners. Rather than theorizing actional-operational modes in terms of the students' or teachers' cultures, therefore, 
this study theorizes the affordances and productive constraints of modes in terms of how well they enabled the communication of earth science concepts as outlined in state standards.

Second, this study is limited in its primary focus on actional-operational modes, which in practice were used in conjunction with other modes, such as the teachers' verbal speech that labeled and explained these modes, and such as the images that appeared in the same instructional episodes. While these other modes (verbal speech; image) are mentioned in the study to contextualize the teachers' use of actional-operational modes, their role in scientific communication is not theorized in this study. This study is further limited due to its focus on earth science, a discipline that relies especially heavily on the analysis of changing spatial positions (Kastens, \& Ishikawa, 2006; Orion \& Ault, 2007). The typology of actional-operational modes outlined in this study may therefore be different from typologies of actional-operational modes used in other scientific disciplines.

Unlike other modes, such as images in textbooks that are distributed to hundreds of classrooms, actional-operational modes are defined in relation to individual body movements. Accordingly, although this typology developed in this study can be used as a heuristic for understanding actional-operational communication, the author does not presume that the body movements that appeared in these three classrooms are the same as the body movements that would appear in other earth science classrooms. The study's transferability is limited in this regard. Moreover, this study is further limited due to the teachers' desire to appeal to an audience of sixth-graders (11- and 12-year-olds). Students' body movements were used to represent a wide range of phenomena such as tidal bulges, planets, molecules, and rock particles, but teachers of older students and teachers of more advanced earth science courses might choose different forms of representations geared toward a different audience. 
Finally, this study's classification system is based on external representations' relationships to their referents, rather than on the external representations' relationships to students' internal representations. Because students' interpretations of these modes were not examined, this study does not enable inferences in regards to which types of representation may foster more in-depth learning of earth science. However, because there are presumed relationships between external representations and students' internal representations (Larkin \& Simon, 1987; Prain \& Tytler, 2012), this study provides a basis from which future studies on students' interpretations of actional-operational modes can be conducted.

\section{Findings}

The following section provides general information about the teachers' use of actionaloperational modes. It then addresses each research purpose by defining the categories of actional-operational modes used in the three teachers' instruction. For each major category, the mode is described in terms of its affordances and productive constraints in relation to the ideational, interpersonal, and textual metafunctions of communication.

\section{Teachers' Use of Actional-Operational Modes}

As indicated by Table 1, actional-operational modes appeared with regularity across the three earth science teachers' instruction, although the prevalence of these modes varied from teacher to teacher. Nancy Rae, who had taught language arts for 16 years (and earth science for seven), described her favorite teacher as one who "would have us write in a journal" and "would read books out loud and we would listen to them...[and] we would all have our own copy and read it while he was reading aloud." The only teacher in the study who was endorsed in teaching reading, Nancy Rae selected textbook sections to communicate scientific concepts more often than she used any single type of actional-operational mode (aside from gesture) because she believed that textbooks "gave [students] background information" in articulated and accessible 
ways, whereas she felt students did not always understand the targeted scientific concepts behind experiments and embodied representations.

Tracy and Grace, in contrast, respectively described their favorite teacher as one who "did a lot of hands-on...did a lot of labs; we didn't do bookwork" and "you built your understanding of it [science] through your experiences versus just reading some paragraphs...it wasn't just writing something on paper, it was actually doing the things to help me understand it." Their instruction accorded with this "hands-on" philosophy: Grace and Tracy both used several types of actional-operational texts more often than they used their textbooks.

Despite this variation in the frequency with which teachers used actional-operational modes, the three teachers collectively ranked actional-operational modes as being their most useful communicative tool in $85.71 \%(n=14)$ of the instructional episodes about which they were interviewed (see Figure 2). Even Nancy Rae, when interviewed about four instructional episodes, identified one or more actional-operational modes as the most useful mode(s) of representation in each interview.

Moreover, when asked at the end of the year to identify the most effective unit she taught, Nancy Rae named her unit on lunar phases due to her use of a variety of three-dimensional models and two-dimensional manipulatives. In her words, "they were something in their hands, something in front of them they could work and see. I think that was the most important; I think that's what helped them to answer questions about placement of the earth, moon, and sun." As this quote suggests, even Nancy Rae, who placed a high value on written texts, also highly valued actional-operational modes, identifying them as more effective than other modes at conveying scientific information in several cases.

At the same time, in $21.43 \%(n=14)$ of instructional episodes about which teachers were interviewed, an actional-operational mode was also identified as the least helpful mode in terms 
of how well it communicated earth science concepts to students. In other words, when the mode aptly afforded the communication of aspects of the referent that were salient to teachers, they ranked that mode more highly than when they believed other modes more clearly communicated aspects of the referent. The following section describes the affordances and constraints of a variety of actional-operational modes, identifying situations in which teachers found them particularly useful and when they did not.

\section{Body as Text: Gesture and Embodied Representation}

Through their verbal speech, all three teachers drew attention to the movement, shape, and speed of their hands and arms; they used hand/arm movements to laminate and extend the information in other modes; and they asked students to move their own bodies in particular configurations to represent a variety of scientific phenomena. When body movements or positions were used to communicate scientific concepts in one of these ways, the data point was coded 'body as text.' When identifying instances of 'body as text,' we sought to distinguish between communicative body movement and non-communicative body movement.

According to some research literature (e.g., Erickson, 2004; McDermott, Gospodinoff, \& Aron, 1978), in one sense, all body movements and positions can be considered communications. Lim, O’Halloran, and Podlasov (2012), for example, asserted that teachers who usually stand in the front and center of their classrooms communicate an authoritative stance in regards to the interpersonal metafunction of communication. McNeill (1992) asserted that the up-and-down movements (or 'beats') that accompany verbal speech "do not produce a discernible meaning" (p. 80) yet may still play a textual function by structuring the speaker's discourse. This study, however, excluded beats and bodily spatial positions from the analysis, counting only those body movements and spatial positions as 'communication' when they pointed toward specific aspects of other modes or when their intended meanings were cued by verbal speech. For instance, 
Nancy Rae asked her students to 'show me a transform [tectonic] plate boundary,' to which her students responded by rubbing the inner edges of both hands past each other with palms facing downward.

In some cases, as in the example above, only one part of the body (usually the arms or hands) represented some aspect of a referent or pointed toward another mode. These data points were identified as 'gesture.' In contrast, at other times, students' whole bodies represented an object or phenomenon, such as when Grace, who represented the sun, tugged a student toward herself, while the student wanted to remain in his current state of motion by moving forward in a straight line. The resultant effect of gravity and inertia was the student settling into an orbit by walking around Grace. This latter form of representation was defined as 'embodied representation.'

Ideational metafunction. As indicated by the multimodal concordance charts, an affordance of many embodied representations and gestures was the spatial perspective offered when bodies, limbs, and space were used to represent aspects of three-dimensional referents. One example will illustrate the affordances of embodied representations and gesture in communicating seafloor spreading. At the outset of one lesson, Grace told her students that they represented parts of the oceanic crust while a table in the center of the room was designated as a mid-ocean ridge. To illustrate the movement of oceanic crust away from the mid-ocean ridge, Grace lifted both arms toward the center of the room, then moved her left arm to the far left and her right arm to the far right, stating that her arms, which represented the movement of the seafloor away from the ridge, had hit a 'subduction zone.'

At this point, she swept both arms downward and explained that the oceanic crust would be pushed back into the mantle. Grace's students then identified which parts of the 'crust' (their peers) were younger or older in relation to the 'mid-ocean ridge' (the table); they moved in the 
correct direction (away from the subduction zone); and they verbally identified what would happen to them when they hit the wall (the subduction zone). This embodied representation enabled 'away' from the mid-ocean ridge to appear as 'forward' (if students' backs were to the table), while 'immediate left' and 'immediate right' of a given student designated parts of the seafloor that were the same age as her or him.

Unlike representations bounded on a page or screen, the embodied representations enabled gradations of forward, behind, left, right, and diagonal to be communicated. This affordance enabled students to identify that a student, who was slightly in front and to the right of them, was a particular age of the seafloor as compared to the many other points on the seafloor in the room. Moreover, this representation enabled students to view the same phenomenon from different vantage points (e.g., closer to the 'mid-ocean ridge' or closer to the 'subduction zone') that changed over time.

In addition to affording the representation of the same phenomenon as seen through multiple spatial positions, the embodied mode placed productive constraints on what was communicated about the referent as well. It communicated moving spatial positions over time while omitting the representation of other aspects of the ocean floor, such as its thickness, color, size, and density. These omissions enabled Grace to focus more narrowly on the stated objective of this instructional episode, which was based primarily in an understanding of spatial positioning: to help students identify that older rocks were farther away from the mid-ocean ridge while younger ones were closer, but that their positions were constantly (albeit slowly) changing.

Gestures, like embodied representations, afforded the communication of relative spatial position from multiple perspectives. A brief example will illustrate this affordance of gesture. In an explanation on the causes of a solar eclipse, Grace asked her students to do the following: 
Put your hand up like this [puts right hand up, palm flat and fingers spread, a foot in front of her face]. This is the sun. Put your other hand up like this [puts left hand in a fist between right hand and face]. This is the moon. Your head is the earth. Does the moon go to the backside of the sun [moves left fist behind right hand], or is it between the earth and the sun [returns left fist in between right hand and face]? Look, you can see the sun, maybe just a couple little rays, but this is the solar eclipse, this is when the sun is blocked. When you see a solar eclipse, the sun is shadowed, and you can maybe see just a ring or a little bit of rays around the sun.

This representation afforded the immediate ability to look at the 'sun' from 'Earth,' while also turning to one's partner and seeing the same solar eclipse as it would appear from outer space, with the earth, sun, and the moon all aligned from an outside vantage point. When gestures communicated relative spatial position of two moving or still entities, as in this instance, teachers classified them as among the most useful modes in their instruction.

Interpersonal metafunction. In addition to affording the communication of positions from a variety of spatial perspectives (an ideational affordance), the teachers asserted that 'body as text' held other affordances as well. When describing representations that had been given this code, they explained the purposes and strengths of embodied modes in the following terms: "I wanted to jazz it up and make it more engaging" (Grace); “They're actively engaged here" (Nancy Rae); and it "kept them engaged; kept them interested" (Tracy). Although this study did not collect data on students' motivation, the concept of being 'active' was in one sense confirmed in the analyses of the representations themselves. Unlike other representations that Grace used to teach seafloor spreading, such as a visual diagram in students' textbooks, the students' spatial positions played a significant role in shaping what the representation conveyed 
in relation to its referent. In interpersonal terms, then, this modal category afforded a greater degree of physical participation than many other modes.

Textual metafunction. In terms of the textual metafunction of communication, the 'body as text' exhibited affordances and constraints as well. One role of the textual metafunction is to relate parts of a given text to other parts of the same text. For instance, in the example of the representation of seafloor spreading, it is through the textual metafunction that one student's body at one point in time and space was related to the same body at a different point in time and space. This embodied representation, unlike the students' textbook diagrams that portrayed all aspects of seafloor spreading simultaneously, left no visible traces of previous positions after students' bodies had moved. In effect, no permanent markers connected an earlier moment of the representation to a subsequent moment.

Although this aspect of movement through time may cohere with a referent, in the sense that the seafloor is different at one point in time than it is at another, embodied representations and gestures constrained students' ability to go back and revisit the information conveyed by these modes. This transitory nature of gesture at times caused teachers to rank them as being among their least effective communicative tools. For instance, Nancy Rae lifted her index finger and drew a crescent moon when describing the shape of that phase of the moon, and she repeated similar motions for each lunar phase. She thought this representation was not effective compared to images, which she ranked more highly, because the images afforded a more permanent visualization of the same shape.

\section{Moving Object as Text: Three-Dimensional Space and Flat Surfaces}

Although body movements and positions were often themselves focal texts that represented aspects of referents, in other instances, body movements were instead used to manipulate focal texts. The following section describes one category of non-embodied actional- 
operational texts: 'moving object as text.' This code was applied to data points in which teachers' verbal speech directed students to attend to an object or image's spatial position relative to another object, body, or image; this code was also applied to data points in which teachers asked students to attend to one object or image's spatial position at one point in time as compared to the same object or image's spatial position at another point in time. Although 'body as text' could also be used to communicate relative spatial position over time, as indicated in the example of seafloor spreading, the affordances of 'moving object as text' were distinctive from the affordances of the body. These 'moving objects as text' enabled more precise communication of size, shape, and color in regards to the size, shape, and color of their referents, thereby earning a designation as a separate category.

Two subcategories of 'moving objects as text' emerged from the data analysis. First, at times, students manipulated images (sometimes labeled with words) situated on a flat surface. For example, Nancy Rae asked her students to move three different-sized circles-labeled earth, moon, and sun — in different configurations to represent lunar eclipses, solar eclipses, and lunar phases. As a second example, Tracy's students cut out the shapes of the modern-day continents and tried to place them together as they believed they once appeared in Pangaea. This category was labeled 'moving object as text: flat surface.'

Objects that moved through three-dimensional space, on the other hand, were designated 'moving object as text: three-dimensional space.' The most common objects that moved through three-dimensional space were globes and a variety of spheres used to represent celestial motion and its effects. Examples of this latter type of representation included Tracy's movement of a tilted globe around a light bulb (the sun) to communicate the causes of seasons and Grace's movement of a tilted globe around her students, whom she told were positioned on 'the sun,' to represent the same phenomenon. 
Ideational metafunction. In many ways, the ideational affordances of objects moving through three-dimensional space were similar to those of embodied representation and gesture: They afforded the representation of a given phenomenon from multiple spatial viewpoints, including from the viewpoint of an entity being represented (e.g., viewing a tilted earth revolve from a position on the sun). Students could physically move themselves and, by so doing, change the vantage point from which they viewed the represented phenomenon. When students moved manipulatives across a two-dimensional space, by contrast, a productive constraint was that students were forced to view the phenomenon from one relatively fixed viewpoint.

As one student moved the "puzzle piece" continents to form Pangaea, for example, his implied spatial position was that of somebody at a certain distance away from the earth: far away enough to see the continents in their entirety, but close enough that the continents were still visible. As one student moved the cut-outs representing the earth, moon, and sun, her implied spatial position was of somebody out in space far away from the earth, moon, and sun. Thus, Nancy Rae's paper manipulatives of the planets did not afford the view of a solar eclipse from the earth, as did Grace's gesture.

According to the teachers, this productive constraint of viewing items from a fixed spatial position did not hinder their communication if the salient aspects of the focal phenomenon (as determined by their instructional objective) could be clearly communicated from one vantage point. Understanding many concepts in earth science, however, requires a consideration of how the same phenomena, such as lunar phases or solar eclipses, would appear from multiple vantage points. For these concepts, the teachers ranked representations that had been coded 'moving object as text: three-dimensional space' as among the most useful in helping students reach their instructional objectives. 
In Grace's words, she chose to represent lunar phases through objects moving in threedimensional space because it enabled her students to start to make understanding of why we see the phases of the moon, that half of that ball is always lit, or half of the moon is always lit, and that's the half that's facing the sun, but we don't always see that whole half. [An image and the three-dimensional representation] kind of joined the two perspectives, let me say it that way. So they could see that, even though this half is lit, this is what we see from earth.

Grace's emphasis on spatial perspective-including what could and could not be seen from multiple vantage points - underscores the affordances that stem from the inclusion of threedimensional space in representation. The space around three-dimensional objects enabled students to change their position relative to that object, thereby changing what was seen from their new position.

Interpersonal metafunction. As indicated by the multimodal concordance charts, several interpersonal aspects of instances that had been coded 'moving object as text' were similar to instances that had been coded 'body as text.' In both categories, teachers frequently used terms such as 'enjoyable,' 'engaging,' and 'not boring,' when they described the reasons they used these modes. When describing her use of virtual manipulatives, during which students placed various organisms in corresponding layers of soil, Tracy stated: "Watching a video is great, but when you have it on your own computer and you're the one deciding what happens when, they really like that sense of power. That really got into that. It's definitely something they want to do again." As suggested by this quotation and by the analyses from the MCCs, "moving objects as text' afforded students a high level of participation in one of two senses: their movement shaped the appearance of the representation, thereby influencing what it communicated in relation to its referent; or they could change their spatial position in relation to 
the representation, thereby seeing a new aspect of the referent that was different from what they saw from a different spatial position.

Textual metafunction. 'Moving objects as text' bore similarities to 'bodies as text' in relation to the textual metafunction of communication as well. Both categories were limited in the sense that subcomponents of the text (e.g., the globe at the vernal and autumnal equinox positions in its revolution around 'the sun') unfolded over time, and these subcomponents were often not simultaneously or permanently visible. Some digital versus paper manipulatives offset this textual constraint by enabling students to go back and revisit their initial spatial placements, but in most cases, the intransigence of these modes meant students could not revisit the same text at home with as much ease as they could revisit a textbook image.

\section{Materiality as Text: Observed Phenomenon and Material Representation}

For many modes of communication, the physical composition of the text was not salient to the teachers' instructional objective. For instance, in Grace's teaching of lunar phases, the half-black, half-yellow sphere could have been plastic, rubber, or Styrofoam, yet it still would have enabled Grace to meet the same communicative objective. At other times, however, the medium was the message in the sense that the teachers' verbal speech emphasized one or more aspects of the focal object's materiality, such as its state of matter, physical composition, density, hardness, temperature, texture, and rate at which it heated and cooled.

Therefore, although the final category, 'materiality as text,' also usually entailed the bodily manipulation of three-dimensional objects, this category was distinguishable from the previous category due to the fact that teachers directed students to make inferences related to materiality of the text, or they directed students to make inferences about its physical interactions with other material entities. These inferences were sometimes made through direct observation of an object, such as when Grace's students cut the chocolate-covered cherry. These inferences 
were also made through observing the effects of interactions among two or more objects or entities, such as when Grace's students placed teaspoons of Salol over a flame and watched them cool at room temperature or cool over ice. (Grace included this latter lab to represent the effects of cooling rates on intrusive and extrusive igneous rocks.)

Two categories of 'materiality as text' emerged during coding. First, at times, teachers' verbal speech indicated that the object of study was a representation of an object or phenomenon that was difficult to study due to factors such as the object's size, temperature, or time scale. For instance, Tracy used colored chocolate chips to represent rock particles that underwent various stages of the rock cycle. These texts were coded as 'materiality as text: material representation.' In other cases, students directly manipulated the focal phenomena themselves, such as when Grace's students scratched several unidentified minerals across benchmark minerals on Mohs Hardness Scale to determine which were harder. These texts were coded as 'materiality as text: observed phenomenon.'

Ideational metafunction. Unlike language and images, material representations and observed phenomena are both haptic and visual. Because many phenomena on earth are caused by a variety of physical factors other than their visual appearance, this modal category afforded the direct communication of a variety of physical features, such as hardness, pressure, and relative temperature. Moreover, this modal category often integrated haptic and visual sensory modalities by showing how one affected the other-for instance, by communicating how heat and pressure affected the visual appearance of the colored chocolate chips, by communicating how the property of hardness caused a visually observable scratch, or by communicating how rate of cooling produced differing visually observable crystal sizes.

In 10 of 12 interviews about instructional episodes that included an instance of materiality as text, the teachers ranked this mode as the first or second most effective mode used 
to communicate the targeted concept. In some instances, this ranking was due to the teachers' perception that these modes bore more direct perceptual resemblances to the represented phenomena than other modes. When describing a lab she had planned to teach convection currents to students, Tracy stated:

You have to be able to physically see and manipulate what's going on so that you can really understand what's happening. Because it's kind of hard to read in a description how convection currents work. You can even see diagrams in the book, but they're not moving, and a lot of kids have a hard time interpreting not just what they read, but sometimes graphics, and so they need to be able to have other ways to access the information. And for most kids...I think that the hands-on type stuff is what really helps them to get it.

In this quote, Tracy identified that an affordance of an observed phenomenon was its ability to convey movement in ways not possible with a printed image. Unlike Tracy's textbook diagram, which communicated temperature and directionality of movement through blue and red arrows, Tracy's labs communicated convection through the use of actual heat and movement. She believed the use of arrows, colors, and other mediating signifiers were at times confusing to some students. In this sense, the productive constraints of observed phenomena included the absence of many mediating signs (e.g., arrows), instead focusing students' attention on the direct effects of interactions among materials with various physical properties.

Interpersonal metafunction. This direct perceptual resemblance-which integrated many sensory modalities — was an ideational affordance of many labs, but it was not the primary reason that teachers ranked this modal category as being especially valuable. Instead, they intimated that this type of text was useful because it introduced the students to the social practices of science, especially in regards to how scientists construct understandings of the world 
and what types of knowledge are legitimized in this discipline. All three teachers emphasized that science is a process of inquiry and discovery, one in which practitioners seek for answers from the material world rather than exclusively accepting other people's suppositions as expressed in textbooks, articles, and ready-made diagrams.

In Tracy’s words, “I feel like doing those hands-on labs are really really a big deal. Science is best discovered...I don't really think science is learned best from a textbook." When asked what she wanted her students to come away with in earth science, Nancy Rae similarly stated: "To have a curiosity to know how things work, to have an excitement about exploring and learning and seeing how things work. And having the desire to try and go and find the answers, not just believe what somebody says but actually go out there and say, 'Hey, did this work?' or 'Hey, is this right?'” In each answer, the teachers emphasized that legitimate knowledge in science is constructed in part by students seeking or "discovering" answers themselves in relation to the world "out there," an epistemological stance that they felt was communicated more fully through observed phenomena and material representations than through other modes.

Textual metafunction. In relation to the textual metafunction of communication, Kress (2009; cf. van Leeuwen, 2005) argued that all texts are made coherent in part through the use of a 'frame' that distinguishes one instance of communication from another. A diagram, for instance, is often bounded by blank space or lines around it, indicating a degree of separation from written text in science textbooks. Many actional-operational modes, however, were not bounded by physical markers in a page or book but instead made use of three-dimensional space and materials from the outside world.

In Tracy's words, "Science is not just about learning a bunch of content but learning how to study your surroundings and study the world around you," a sentiment that was echoed by Nancy Rae who stated "science is learning about the world around us and how things act and 
interact." The teachers felt that (in terms of the textual metafunction) material representations and observed phenomena most fully facilitated connections with the "world around students," such as when Grace and Tracy stated that these modes enabled students to look outside in the natural world and see exact instances of materials they had used in class. In other words, the relatively flexible and porous frames of many actional-operational modes, as compared to many other tightly bounded modes, facilitated textual connections with the material world outside of the classroom, a goal that all three teachers named as a purpose of their earth science instruction.

Despite the teachers' appreciation of this final modal category, however, they perceived their utility to be contextual rather than universal, as with other actional-operational modes. In one instance, Nancy Rae ranked an observed phenomenon as being only the third most useful mode (out of four) in a particular lesson on water conservation. She attributed this low ranking to a lack of clear discussion about what the observed phenomenon-water condensation in plastic bags - meant in relation to the water cycle. She said that the observed phenomenon would have been a more useful instructional tool if she had asked "each student [to] tell me what's happening in each bag. What does this represent? What do these water droplets represent? Oh, they represent condensation." In this sense, the teachers believed that observed phenomena and material representations were most useful when their relationships to their referents were clarified through contextualizing information found in other modes. When this contextualizing information was absent, the modes that had been coded 'materiality as text' lost their utility.

\section{Summary of Findings}

This study outlined three major categories of actional-operational modes-body as text, moving objects as text, and materiality as text — and described two sub-categories that appeared under each major category. Overall, the teachers perceived these modes as being among the most useful tools in their instruction, and they used them with regularity. They valued these modes 
due to their ability to communicate phenomena through multiple spatial perspectives, to communicate interactions among haptic and visual modalities, to facilitate connections with the outside world, to give their students a sense of 'power' in shaping what the representation conveyed in relationship to a referent, to foster enjoyment, and to communicate the epistemological stance that science is "best" when discovered for oneself rather than when it is received through reading others' findings.

At the same time, however, the teachers recognized these modes as being potentially problematic. Their oftentimes transitory nature presented problems for students who missed aspects of a given representation; students often had no way of revisiting what the representation communicated at any given particular point in time and space. Moreover, these representations were also problematic if students' spatial positions, bodily actions, and operations did not cohere with their referents in the ways intended by the teacher. Finally, these modes were also problematic when the targeted relationship between the referent and signifier was unclear.

Though materials such as salol, chocolate covered cherries, and chocolate chips communicated haptic and visual aspects of their referents, they also potentially miscommunicated information in the sense that time scales, degree of temperature and pressure, physical composition, and other physical aspects of the representation were profoundly different from those of referent. The teachers accordingly emphasized the necessity of using other visual, written, and verbal representations with the intention of constraining and complementing the interpretations that students drew from the actional-operational modes.

\section{Discussion and Implications}

Many researchers (e.g., Gilbert, 2005; Harrison \& Treagust, 2000; Pozzer-Ardenghi \& Roth, 2005; Prain \& Waldrip, 2006; Topper, 1996) have previously outlined typologies that categorize scientific communication. Some typologies categorized the various forms that can be 
assumed by one mode, such as images (Han \& Roth, 2006; Topper, 1996), while other typologies sought to categorize all types of scientific communication (e.g., Lemke, 1998; Wu \& Puntambekar, 2012). This study offers a complementary perspective to these typologies by proposing an additional typology for one category of scientific communication: actionaloperational modes. Although this mode has been identified as a sub-category in other typologies of scientific representation, they have not articulated how one actional-operational mode differs from another-for instance, how three-dimensional physical models afford different types of communication than lab experiments (Prain \& Waldrip; Wu \& Puntambekar). This study therefore extends and clarifies previous typologies by describing the differences among these categories in greater detail.

Prain and Tytler (2012) argued for the importance of studying the features of scientific representations. They stated that the affordances and productive constraints "offered by particular representational modes and tasks enable reasoning and learning precisely because of the specific ways they channel attention, and force choices by the person or group constructing the representation" (p. 2759). This study sought to describe how the affordances and productive constraints of actional-operational modes channeled attention in particular ways, such as how the embodied representation of seafloor spreading forced students to make choices in relation to spatial position and directionality when they decided where they would stand in relation to other bodies. This representation channeled attention toward spatial position by omitting other aspects of its referent, such as its temperature or composition. By understanding how the material features of representations afford and productively constrain communication in relation to a referent, as outlined in this study, teachers can more purposefully select representations that direct students' attention toward focal aspects of the referent, including representations that complement the information conveyed by other external representations (Ainsworth, 1999). 
In addition to offering implications for teachers' representational selections, this study points toward other issues that teachers can consider as they seek to explicitly support students in comprehending, evaluating, and producing representations. Researchers of science literacy instruction (Greenleaf et al., 2011; Yore \& Treagust, 2006; Yore \& Hand, 2010) have suggested that teachers can explicitly support students' interpretations of texts in at least two ways: (a) by providing comprehension strategy instruction on these texts and (b) by building students' multimodal representational competence. This section concludes by using the features of actional-operational modes to speculate on how comprehension strategy instruction and instruction in multimodal representational competence might be re-conceptualized to more rigorously account for these modes' features.

\section{Comprehension Strategy Instruction and Actional-Operational Modes}

A large body of research literature (e.g., Greenleaf et al., 2011; Klein, 2006; Koch, 2001; Leopold \& Leutner, 2012) has sought to document the effects of explicit literacy instruction on students' interpretations of printed scientific texts, suggesting that comprehension improves as students apply comprehension strategies such as inferring, predicting, summarizing, visualizing, and asking clarification questions while they read. Moje (2008) and Conley (2008) have critiqued much of this previous research on comprehension strategy instruction in science and other disciplines, arguing that this research has not heretofore accounted for the distinctive literacy practices required by particular types of communication in each discipline.

To respond to this critique, researchers and teachers may consider ways that they can modify comprehension strategy instruction to account for the unique features of actionaloperational modes. In reading printed texts, for example, 'effective' readers often draw from their prior knowledge and use text features such as headings to make predictions about a text's content; they confirm and revise their predictions as they read; and they reread sections that are 
still unclear to them (Duke et al., 2011). Actional-operational modes, however, often do not exhibit comparable features on which to base predictions, such as headings and other stable visual features that can be revisited. Consequently, these texts may require certain kinds of predictions based on relatively unstable physical features that are often spatio-temporal or tactile in nature.

As a second example, Alvermann (2004) noted that self-questioning helps students comprehend a variety of modes in the science classroom, but she did not address the ways these questions might differ depending on the mode. The features of actional-operational modes invite questions not applicable to most written texts, such as "How might this representation appear differently if I viewed it from another angle?" and "How is the visual appearance of the representation affected by its material properties?" Further research can be conducted to determine whether this type of modified comprehension strategy instruction can enhance students' interpretation of a variety of actional-operational modes.

\section{Multimodal Representational Competence and Actional-Operational Modes}

Multimodal representational competence (Yore \& Hand, 2010) has also been described as a heuristic that can enhance students' fundamental scientific literacy skills. The concept of multimodal representational competence draws from earlier work in meta-representational competence (e.g., diSessa \& Sherin, 2000), which is defined in part as the ability to "invent or design new representations; critique and compare the adequacy of representations and judge their suitability for particular tasks; ... understand how representations do the work they do for us; and explain representations" (diSessa, 2004, p. 293; cf. Greeno \& Hall, 1997).

Kozma and Russell's (1997) definition of 'representational competence' similarly included the ability to analyze features of individual representations and to use them to explain phenomena, but it focused more heavily on translations across various categories of 
representation. For instance, the authors argued that students should be able to translate one form of representation to another (cf. Gilbert, 2005), to explain the relationship between both representations, and to "describe how different representations might say the same thing in different ways and how one representation might say something that cannot be said with another" (p. 964).

Although Kozma and Russell (1997) and diSessa (2004) worked with modes that primarily appeared on paper or on computer screens, the concept of 'multimodal representational competence' can also be used to apply to a variety of actional-operational modes. (Here, the term 'multimodal representational competence' is used to encompass aspects of both metarepresentational competence and representational competence.) Nancy Rae's students, for example, could compare and contrast the two-dimensional paper manipulatives of the earth, sun, and moon with the three-dimensional representation in which students revolved a Styrofoam ball (representing the moon) around their heads (representing the earth), while a light bulb in the middle of the darkened room represented the sun.

Students could note that what was communicated through one representation (e.g., the perspective of a lunar phase from the earth) was not effectively communicated with the other representation (e.g., the paper manipulatives which presented the phenomenon from a perspective in outer space). After discussing the affordances and constraints of various actionaloperational modes and other scientific communications, they could produce and critique their own representations and judge their suitability for accomplishing their purposes.

These student representations, however, need not be limited to paper-and-pencil modes or to digital modes, as has been suggested in much of the previous literature on scientific representation. Instead, they could include a wide variety of actional-operational modes as well. Kozma and Russell (1997) suggested that chemistry students who could translate among a 
variety of representations and explain how they related to each other developed a deeper understanding of concepts in chemistry; further research can be conducted to determine whether this approach to actional-operational modes would engender deeper understandings of concepts in earth science as well.

To be clear, although this study describes the affordances and constraints of actionaloperational modes, its purpose is not to suggest that earth science is or should be entirely 'handson.' On the contrary, printed texts that include written language, images, numerical tables, and other modes of representation are also central to the work of practitioners of science. This study does suggest, however, that definitions of 'scientific literacy' — or the ability to interpret and produce scientific texts (Norris \& Phillips, 2003)—can be expanded to include students' interpretation and production of actional-operational modes as well as their interpretation and production of printed and digital texts.

Greenleaf et al. (2011), in their study of the effects of fundamental scientific literacy instruction, did not include actional-operational modes as legitimate objects of literacy instruction, instead arguing that teachers used them in order to "avoid the problem of students' lack of academic literacy proficiency" (p. 658), which the authors equated with their ability to read textbooks, lab reports, and other printed modes. This study calls for a more balanced approach to science literacy instruction, one that recognizes actional-operational modes as legitimate texts from which students construct interpretations about earth and its systems, and one that recognizes actional-operational modes as potentially legitimate texts through which students can express their understandings. 


\section{References}

Ainsworth, S. (1999). The functions of multiple representations. Computers and Education, 33, $131-152$.

Ainsworth, S. (2006). DeFT: A conceptual framework for considering learning with multiple representations. Learning and Instruction, 16, 183-198.

Alvermann, D. E. (2004). Multiliteracies and self-questioning in the service of science learning. In E. W. Saul (Ed.), Crossing borders in literacy and science instruction: Perspectives on theory and practice (pp. 226-238). Newark, DE: International Reading Association and National Science Teachers Association.

Balaban, A. T. (1999). Visual chemistry: Three-dimensional perception of physical structures. Journal of Science Education and Technology, 8, 251-255.

Baldry, A., \& Thibault, P. J. (2006). Multimodal transcription and analysis: A multimedia toolkit and coursebook with associated on-line course. London: Equinox.

Bazerman, C. (1988). Shaping written knowledge: The genre and activity of the experimental article in science. Madison, WI: University of Wisconsin Press.

Conley, M. (2008). Cognitive strategy instruction for adolescents: What we know about the promise, what we don't know about the potential. Harvard Educational Review 78, 84108.

Corbin, J., \& Strauss, A. (2008). Basics of qualitative research: Techniques and procedures for developing grounded theory ( $3^{\text {rd }}$ ed.). London: SAGE.

Crowder, E. M. (1996). Gestures at work in sense-making science talk. The Journal of the Learning Sciences, 5, 173-208.

diSessa, A. A. (2004). Meta-representation: Native competence and targets for instruction. Cognition and Instruction, 22, 293-331. 
diSessa, A. A., \& Sherin, B. L. (2000). Meta-representation: An introduction. Journal of Mathematical Behavior, 19, 385-398.

Duke, N. K., Pearson, P. D., Strachan, S. L., \& Billman, A. K. (2011). Essential elements of fostering and teaching reading comprehension. In S. J. Samuels \& A. E. Farstrup (Eds.), What research has to say about reading instruction $\left(4^{\text {th }}\right.$ ed., pp. 51-93). Newark, DE: International Reading Association.

Erickson, R. (2004). Talk and social theory: Ecologies of speaking and listening in everyday life. Malden, MA: Polity Press.

Fang Z. (2006). The language demands of science reading in middle school. International Journal of Science Education, 28, 491-520.

Gibson, J. J. (1979). The ecological approach to visual perception. Boston: Houghton Mifflin.

Gilbert, J. K. (2005). Visualization: A metacognitive skill in science and science education. In J. K. Gilbert (Ed.). Visualization in science education (pp. 9-27). Dordrecht, Netherlands: Springer.

Goodwin, C. (2000). Action and embodiment within situated human interaction. Journal of Pragmatics, 32, 1489-1522.

Greenleaf, C. L., Litman, C., Hanson, T. L., Rosen, R., Boscardin, C. K., Herman, J., Schneider, S. A., Madden, S., \& Jones, B. (2011). Integrating literacy and science in biology: Teaching and learning impacts of reading apprenticeship professional development. American Educational Research Journal, 48, 647-717.

Greeno, J. G., \& Hall, R. P. (1997). Practicing representation: Learning with and about representational forms. Phi Delta Kappan, 78, 361-367.

Halliday, M. A. K. (1973). Explorations in the functions of language. London: Edward Arnold. 
Halliday, M. A. K. (1978). Language as social semiotic: The social interpretation of language and meaning. London: Arnold.

Han, J., \& Roth, W.-M. (2006). Chemical inscriptions in Korean textbooks: Semiotics of macroand micro-world. Science Education, 90, 173-201.

Harrison, A. G., \& Treagust, D. F. (2000). A typology of school science models. International Journal of Science Education, 84, 352-381.

Hodge, R., \& Kress, G. (1988). Social semiotics. Ithaca, NY: Cornell University Press.

Jewitt, C. (2006). Technology, literacy, and learning: A multimodal approach. London: Routledge.

Kastens, K. A., \& Ishikawa, T. (2006). Spatial thinking in the geosciences and cognitive sciences: A cross-disciplinary look at the intersection of the two fields. In C. A. Manduca \& D. W. Mogk (Eds.) Earth and mind: How geologists think and learn about the earth (pp. 53-76). Boulder, CO: Geological Society of America.

Kendon, A. (2004). Some contrasts in gesticulation in Neapolitan speakers and speakers in Northamptonshire. In R. Posner \& C. Mueller (Eds.), The semantics and pragmatics of everyday gesture (pp. 173-193). Berlin: Weidler Buchverlag.

Klein, P. D. (2006). The challenges of scientific literacy: From the viewpoint of secondgeneration cognitive science. International Journal of Science Education, 28, 143-178.

Klein, P. D., \& Kirkpatrick, L. C. (2010). Multimodal literacies in science: Currency, coherence, and focus. Research in Science Education, 40, 87-92.

Koch, A. (2001). Training in metacognition and comprehension of physics texts. Science Education, 85, 758-768.

Kozma, R. B. (2003). The material features of multiple representations and their cognitive and social affordances for science understanding. Learning and Instruction, 13, 205-226. 
Kozma, R., B., \& Russell, J. (1997). Multimedia and understanding: Expert and novice responses to different representations of chemical phenomena. Journal of Research in Science Teaching, 34, 949-968.

Kress, G. (2003). Literacy in the new media age. London: Routledge.

Kress, G. (2005). Gains and losses: New forms of texts, knowledge, and learning. Computers and Composition, 22, 5-22.

Kress, G. (2009). What is mode? In C. Jewitt (Ed.), The Routledge handbook of multimodal analysis (pp. 54-67). London: Routledge.

Kress, G. (2010). Multimodality: A social semiotic approach to contemporary communication. New York: Routledge.

Kress, G., Jewitt, C., Ogborn, J., \& Tsatsarelis, C. (2001). Multimodal teaching and learning: The rhetoric of the science classroom. New York: Continuum.

Leopold, C., \& Leutner, D. (2012). Science text comprehension: Drawing, main idea selection, and summarizing as learning strategies. Learning and Instruction, 22, 16-26.

Larkin, J. H., \& Simon, H. A. (1987). Why a diagram is (sometimes) worth ten thousand words. Cognitive Science, 11, 65-100.

Lemke, J. L. (1998). Multiplying meaning: Visual and verbal semiotics in scientific text. In J. R. Martin \& R. Veel (Eds.), Reading science: Critical and functional perspectives on discourses of science (pp. 87-113). London: Routledge.

Lemke, J. L. (2003). Mathematics in the middle: Measure, picture, gesture, and word. In M. Anderson, A. Saenz-Ludlow, S. Zellweger, S. Cifaerelli, \& V. V. Cifarelli (Eds.), Educational perspectives on mathematics as semiosis: From thinking to knowing (pp. 215-234). Ottowa: Legas. 
Lim, F. V., O’Halloran, K. L., \& Podlasov, A. (2012). Spatial pedagogy: Mapping meanings in the use of classroom space. Cambridge Journal of Education, 42, 235-251.

Lincoln, Y. S., \& Guba, E. G. (1985). Naturalistic inquiry. Thousand Oaks, CA: Sage.

McDermott, R. P., Gospodinoff, K., \& Aron, J. (1978). Criteria for an ethnographically adequate description of concerted activities and their contexts. Semiotica, 24, 263-275.

McDiarmid, G. W.,Ball, D. L., \& Anderson, C. W. (1989). Why staying one chapter ahead doesn’t really work: Subject-specific pedagogy. In M. C. Reynolds (Ed.), Knowledge base for the beginning teacher (pp. 193-205). New York: Pergamon.

McNeill, D. (1992). Hand and mind: What gestures reveal about thought. Chicago, IL: University of Chicago Press.

Moje, E. B. (2008). Foregrounding the disciplines in secondary literacy teaching and learning: A call for change. Journal of Adolescent \& Adult Literacy, 52, 96-107.

Norris, S. P., \& Phillips, L. M. (2003). How literacy in its fundamental sense is central to scientific literacy. Science Education, 87, 224-240.

Orion, N., \& Ault, C. R., Jr. (2007). Learning earth science. In S. K. Abell \& N. G. Lederman (Eds.), Handbook of Research on Science Education (pp. 653-687). Mahwah, NJ: Lawrence Erlbaum.

Pozzer-Ardenghi, L., \& Roth,W.-M. (2005). Photographs in lectures: Gestures as meaningmaking resources. Linguistics \& Education, 15, 275-293.

Prain, V., \& Tytler, R. (2012). Learning through constructing representations in science: A framework of representational construction affordances. International Journal of Science Education, 34, 2751-2773. 
Prain, V., \& Waldrip, B. (2006). An exploratory study of teachers' and students' use of multimodal representations of concepts in primary science. International Journal of Science Education, 28, 1843-1866.

Prain, V., \& Waldrip, B. (2010). Representing science literacies: An introduction. Research in Science Education, 40, 1-3.

Rex, L. (2001). The remaking of a high school reader. Reading Research Quarterly, 36,288-314.

Roth, W-M., \& Lawless, D. V. (2002). When up is down and down is up: Body orientation, proximity, and gestures as resources. Language in Society, 31, 1-28.

Roth, W-M., \& McGinn, M. K. (1998). Inscriptions: Toward a theory of representing as social practice. Review of Educational Research, 68, 35-59.

Roth, W-M., Tobin, K., \& Shaw, K. (1997). Cascades of inscriptions and the re-presentation of nature: How numbers, tables, graphs, and money come to re-present a rolling ball. International Journal of Science Education, 19, 1075-1091.

Siskin, L. S. (1994). Realms of knowledge: Academic departments in secondary schools. London: Falmer Press.

Stake, R. E. (2006). Multiple case study analysis. New York: Guilford.

Topper, D. (1996). Toward an epistemology of scientific illustration. In B. S. Baigrie (Ed.), Picturing knowledge: Historical and philosophical problems concerning the use of art in science (pp. 215-249). London: University of Toronto Press.

Tsui, C-Y., \& Treagust, D. F. (2003). Genetics reasoning with multiple external representations. Research in Science Education, 33, 111-135.

van Leeuwen, T. (2005). Introducing social semiotics. London: Routledge.

Waldrip, B., Prain, V., \& Carolan, J. (2010). Using multi-modal representations to improve learning in junior secondary science. Research in Science Education, 40, 65-80. 
Wilson, A. A. (2010). The nature of texts used in five academic disciplines. In R. T. Jiménez, V. J. Risko, D. W. Rowe, \& M. K. Hundley (Eds.), The 59th Yearbook of the National Reading Conference (pp. 154-170). Oak Creek, WI: National Reading Conference, Inc.

Wu, H-K., \& Puntambekar, S. (2012). Pedagogical affordances of multiple representations in scientific processes. Journal of Science Education and Technology, 21, 1-14.

Yore, L. D., \& Hand, B. (2010). Epilogue: Plotting a research agenda for multiple representations, multiple modality, and multimodal representational competency. Research in Science Education, 40, 93-101.

Yore, L. D., \& Treagust, D. F. (2006). Current realities and future possibilities: Language and science literacy — empowering research and informing instruction. International Journal of Science Education, 28, 291-314. 
Author's Note: This material is based upon work supported by the National Academy of Education's Adolescent Literacy Predoctoral Fellowship under the sponsorship of the Carnegie Corporation of New York. Any opinions and findings expressed in this material are those of the author and do not necessarily reflect the views of the National Academy of Education or the Carnegie Corporation. 
